\title{
TNF -308G > A promoter polymorphism (rs1800629) and outcome from critical illness
}

\begin{abstract}
Background: The susceptibility to adverse outcome from critical illness (occurrence of sepsis, septic shock, organ dysfunction/failure, and mortality) varies dramatically due to different degrees of inflammatory response. An over expression of tumor necrosis factor alpha (TNF- $\alpha$ ) can lead to the progression of the inflammatory condition. Objective: We assessed the relationship of the genotype distribution of $-308 \mathrm{G}>\mathrm{A}$ TNF-a polymorphism with regard to the development of sepsis, septic shock, higher organ dysfunction or mortality in critically ill patients. Methods: Observational, hospital-based cohort study of 520 critically ill Caucasian patients from southern Brazil admitted to the general ICU of São Lucas Hospital, Porto Alegre, Brazil. Patients were monitored daily from the ICU admission day to hospital discharge or death, measuring SOFA score, sepsis, and septic shock occurrences. The $-308 \mathrm{G}>\mathrm{A}$ TNF- $\alpha$ SNP effect was analyzed in the entire patient group, in patients with sepsis (349/520), and in those who developed septic shock (248/520). Results: The genotypic and allelic frequencies were $-308 \mathrm{GG}=0.72 ;-308 \mathrm{GA}=0.27 ;-308 \mathrm{AA}=0.01 ;-308 \mathrm{G}=0.85 ;-308 \mathrm{~A}=0.15$. No associations were found with sepsis, septic shock, organ dysfunction, and/or mortality rates among the TNF- $\alpha$ genotypes. Our results reveal that the -308G >A TNF- $\alpha$ SNP alone was not predictive of severe outcomes in critically ill patients. Conclusion: The principal novel input of this study was the larger sample size in an investigation with -308G > A TNF- $\alpha$ SNP. The presence of -308A allele is not associated with sepsis, septic shock, higher organ dysfunction or mortality in critically ill patients.
\end{abstract}

Keywords: polymorphism, single nucleotide; tumor necrosis factor receptor; associated peptides and proteins; critical care.

[Braz J Infect Dis 2011;15(3):231-238]@Elsevier Editora Ltda.

\section{INTRODUCTION}

Among ICU patients the rate of adverse outcomes (occurrence of sepsis, septic shock, organ dysfunction/failure, and mortality) is still high and often uncontrolled despite efforts. ${ }^{1}$ The susceptibility to adverse outcomes in critically ill patients varies dramatically due to different degrees of inflammatory response to infections. This may be due, at least in part, to individual genetic variables of patients facing critical illness. Exo- or endogenous antigens initiates signal transduction cascades inside cells leading to the translocation of NF- $\kappa \mathrm{B}$ into the nucleus where it regulates the expression of pro-inflammatory cytokines. ${ }^{2-4}$ Activated macrophages secrete pro-inflammatory cytokines like TNF- $\alpha$ which initiates the cascade of immunity response. ${ }^{5}$ TNF- $\alpha$ is a pleiotropic cytokine mainly produced by activated monocytes and macrophages, which plays a key role in the inflammatory response. ${ }^{6}$ Inappropriate expression or over expression of TNF- $a$ can lead to the progression of inflammatory and autoimmune diseases, and its administration reproduces essentially all the deleterious effects of endotoxin and/or microorganisms attack, including hypotension, activation of the coagulation cascade, and organ dysfunction. ${ }^{7-9}$ The TNF- $\alpha$ gene is located in the major histocompatibility complex (MHC) region, and a large number of polymorphisms of its promoter have been described. ${ }^{10-12}$ A single nucleotide polymorphism (SNP) at nucleotide $-308(-308 \mathrm{G}>\mathrm{A}$, relative to the transcription start site) in the TNF- $a$ gene promoter region may be important in determining host TNF- $\alpha$ response. The SNP - 308G > A has been associated with inducible levels of TNF- $\alpha$ in vitro, where the change of a guanidine (common $-308 \mathrm{G}$ allele) to an adenosine (rare -308A allele) results in differential binding of nuclear
Authors

Diego D’Ávila Paskulin Paulo RV Fallavena ${ }^{2}$ Francis JO Paludo ${ }^{2}$ Thiago J Borges ${ }^{3}$ Juliane B Picanço ${ }^{2}$ Fernando S Dias ${ }^{4}$ Clarice Sampaio Alho ${ }^{4}$

${ }^{1} \mathrm{MSc}$; PhD Student, Universidade Federal do Rio Grande do Sul (UFRGS), Brazil ${ }^{2} \mathrm{MSc}$; PhD Student, Pontifícia Universidade Católica do Rio Grande do Sul (PUCRS), Brazil ${ }^{3}$ Biologist, MSc Student, PUCRS, Brazil ${ }^{4} \mathrm{PhD}$, Researcher, PUCRS, Brazil

Submitted on: 12/01/2010 Approved on: 02/06/2011

Correspondence to: Clarice Sampaio Alho Av. Ipiranga, 6681 P12 $2^{\circ}$ andar Porto Alegre, RS, Brazil 90619-900

Phone (fax): 5551

33203545 csalho@pucrs.br

Financial Support: FAPERGS/MS/CNPq/ SESRS; EFP00000829; PPSUS-Edital 002/2009 Process \# 09/0039-3

We declare no conflict of interest. 
factors, leading to six to sevenfold increase in the inducible level of TNF- $\alpha$ gene transcription. ${ }^{13,14}$ Thus, the presence of $-308 \mathrm{~A}$ allele could be dangerous to critically ill patients. The -308 polymorphism could potentially affect the celltype and stimulus specific regulation of TNF- $a$ synthesis at the transcriptional level. A genetic propensity to produce elevated TNF- $\alpha$ levels, due to the presence of the $-308 \mathrm{~A}$ allele, may alter the course of an immune response with subsequent increased risk of disease. ${ }^{15}$ Systemic administration of TNF- $\alpha$ produces most of the symptoms and signs of sepsis, and although a number of studies have found associations of the $-308 \mathrm{~A}$ allele with a predisposition to septic shock and/ or outcome from sepsis, findings have been inconsistent. ${ }^{16-24}$

In order to clarify the potential role of the $-308 \mathrm{G}>\mathrm{A} \mathrm{SNP}$ we tested 520 patients for the presence of $-308 \mathrm{~A}$ allele influencing the outcome of critical illness, leading patients to sepsis, septic shock, higher organ dysfunction, and/or mortality.

\section{MATERIALS AND METHODS}

This study was an observational, hospital-based cohort study of patients admitted to the medical and surgical Intensive Care Unit (ICU) of the Hospital São Lucas (HSL) of the Pontifícia Universidade Católica do Rio Grande do Sul (PUCRS), Brazil, between January $1^{\text {st }}, 2004$, and December $31^{\text {st }}$, 2006. Patients were not eligible if they were diagnosed with HIV-infection, taking immunosuppressive drugs, pregnant or lactating, or of non-Caucasian ancestry. The study was approved by the Research Ethics Committee of the institution (protocols \#03-01732, and \#05-02357; REC Tel.: $+55+51$ 33203345). After informed consent was obtained, a total of 520 critically ill adult patients from southern Brazil (277 males and 243 females) admitted to the ICU at HSL-PUCRS were included in this study.

\section{Phenotyping}

We monitored the patients daily during their entire ICU and post-ICU (hospital) stay, to ascertain sepsis and septic shock occurrences until hospital discharge or death. For diagnosis of sepsis and septic shock we used the American College of Chest Physicians/Society of Critical Care Medicine Consensus Conference Criteria. ${ }^{25}$ For illness severity evaluation we used the Acute Physiology and Chronic Health Evaluation II (APACHE-II) score obtained on the ICU admission day. ${ }^{26}$ Organ dysfunction/failure was evaluated using the Sequential Organ Failure Assessment (SOFA) score ${ }^{27}$ obtained during the first seven days following ICU admission and at days 15 and 29. The patients' follow-up was extended up to the entire hospital stay since the ICU admission to a maximum of 242 days. Clinical endpoints of the study were discharge from the hospital (survivors) or death (non-survivors). Mortality was measured in days until death. For those patients with multiple ICU admission during the study period, only data from the first admission was considered.

\section{Genotyping}

Five milliliters of blood were collected in a sterile system with EDTA and maintained refrigerated at $4^{\circ} \mathrm{C}$ or frozen at $-20^{\circ} \mathrm{C}$ until DNA extraction. Genomic DNA was isolated from leucocytes by standard procedures and maintained at $-20^{\circ} \mathrm{C} .{ }^{28}$ For genotyping TNF- $\alpha$ -308G > A SNP (rs1800629), DNA samples were amplified by polymerase chain reaction (PCR) with forward primer TNF- $\alpha-F$ 5-AGG CAA TAG GTT TTG AGG G $\neg$ CC AT-3 and reverse primer TNF- $\alpha-\mathrm{R} 5$-ACA CTC CCC ATC CTC CCT GCT-3 (Invitrogen-Life Technologies, São Paulo, SP, Brazil) in which the underlined nucleotide represents the deliberated primer mismatch designed to introduce an artificial NcoI restriction site when the G allele is present at position -308. A $116 \mathrm{bp}$ PCR product was obtained from a $25 \mu \mathrm{L}$ reaction mix containing 10-50 ng DNA, $1 \mu \mathrm{M}$ each primer, $0.4 \mathrm{mM} \mathrm{dNTP}, 1.5 \mathrm{mM} \mathrm{MgCl}_{2}$ and $1 \mathrm{U}$ Taq polymerase in Taq $1 \times$ Buffer (LGC Biotecnologia, Cotia, SP, Brazil). The reaction was carried in a PTC100 thermocycler (MJ Research, Watertown, MA, USA) as follows: $95^{\circ} \mathrm{C}$ for 2 minutes; 35 cycles of $95^{\circ} \mathrm{C}$ for $30 \mathrm{sec}, 60^{\circ} \mathrm{C}$ for $15 \mathrm{sec}$ and $74^{\circ} \mathrm{C}$ for $15 \mathrm{sec}$; and $74^{\circ} \mathrm{C}$ for 10 minutes for final extension. The PCR amplified product $(12 \mu \mathrm{L})$ was cleaved in an appropriate buffer with 10 U of the NcoI (5 '-C/CATGG-3 '; GibcoBRL ${ }^{\circ}$-Life Technologies ${ }^{\text {tw }}$, Rockville, MD, USA) in a total volume of $15 \mu \mathrm{L}$ at $37^{\circ} \mathrm{C}$ for 16 hours, and digested or undigested samples were visualized by electrophoresis in 3\% agarose gel with GelRed Nucleic Acid Stain (Biotium Inc. Hayward, CA) against a 100-bp ladder. A single band at $116 \mathrm{bp}$ identified -308AA homozygotes, two bands at 96 and 20 bp identified -308GG homozygotes, and three bands at 116, 96 and $20 \mathrm{bp}$ indicated heterozygotes at the -308 TNF-a locus. Each patient found to have-308AA or-308GA genotypes were subjected to a second, independent PCR restriction fragment length-polymorphism analysis in order to confirm their genotypes.

In order to confirm that the $116 \mathrm{bp}$ PCR amplified product really represented the target product, we performed a sequence analysis in MegaBase 1000 capillary DNA sequencer (Amersham Biosciences UK Ltd, Chalfont St Giles, Bucks, UK), also using the designed primers (forward and reverse). The sequence obtained was submitted to a nucleotide-nucleotide BLAST online alignment (blast, at http://www.ncbi.nlm.nih.gov/BLAST/) with the databases, and we found consensus with the Homo sapiens tumor necrosis factor- $\alpha$ gene, promoter region (GenBank accession X02910). All personnel involved in patient care were blind to the selection process and genotyping results. Based on the information that $-308 \mathrm{~A}$ allele leads to six to sevenfold increase in the TNF- $\alpha$ transcription level ${ }^{13,14}$ we use dominant model to -308A allele to perform our analysis. We believe that the co-dominant or recessive models are not applicable in this case since there is a quantitative transcriptional effect of one allele. 


\section{Statistical analysis}

Statistical calculations were performed using the statistical package SPSS 13 (SPSS 13.0 for Windows, Chicago, Illinois, USA). Unless otherwise stated, continuous variable results are expressed as a mean \pm standard deviation (SD), and categorical variables as frequencies and percents. Means were compared using one-way analysis of variance, and non-normally distributed variables were analyzed as non-parametric using Mann-Whitney test. For the categorical data we used Pearson chi-square test, also used to test for Hardy-Weinberg equilibrium. To evaluate the influence of individual genotype on the patient outcome, excluding other risk factors that could influence the outcome, we used binary logistic regression analysis, incorporating patients with and without $-308 \mathrm{~A}$ allele and two main clinical predictors, age, and SOFA-1 score. All reported p-values are two-tailed and considered statistically significant when 0.05 or less.

\section{RESULTS}

A total of 947 patients were admitted to the ICU during the study period, of which 535 were eligible for analysis according the inclusion/exclusion criteria (Figure 1). We performed the analysis of susceptibility to sepsis, septic shock, and mortality according -308G > A SNP using the dominant model to -308A allele (pooling -308GA and -308AA genotypes) and confirming that other important variables, such as gender, age, or diagnosis were otherwise matched between the two genotype groups (Table 1). The general genotypic and allelic frequencies were $-308 \mathrm{GG}=0.72$ $(374 / 520) ;-308 \mathrm{GA}=0.27(141 / 520) ;-308 \mathrm{AA}=0.01(5 / 520)$; $-308 \mathrm{G}=0.85 ;-308 \mathrm{~A}=0.15$, which did not differ from the values expected by the Hardy-Weinberg model ( $\mathrm{p}=0.391$; Pearson Chi-square test). The main medical cause of admission to ICU was sepsis (35\%), followed by respiratory failure $(24 \%)$ and the main surgical cause was abdominal (11\%). In ICU, $67 \%(349 / 520)$ of patients had severe sepsis, and $71 \%$ of them (248/349) evolved to shock. Fluid samples of patients with severe sepsis were positive for Gram-negative bacteria only in 26\% (91/349), Gram-positive bacteria only in 5\% (18/349); both Gram-negative and positive bacteria in $14 \%$ (49/3497); fungi only in $2 \%(7 / 349)$ and fungal and bacterial infection in 5\% (16/349). In 48\% (167/349) no pathogens were identified. The anatomical distribution of the primary site of infection in septic patients was as follows: 66\% (230/349) pulmonary, 24\% (84/349) abdominal, $3 \%$ (10/349) urinary, $1 \%(4 / 349)$ central nervous system, $1 \%$ (3/349) skin, and 5\% (18/349) another site. Age, APACHE-II and SOFA scores, and mortality rates are shown in Table 1. Patient mortality was positively associated with older age, higher APACHE-II and SOFA-1 scores, sepsis and septic shock occurrences (all $\mathrm{p}<0.01$; data not shown).

When we analyzed the $-308 \mathrm{G}>\mathrm{A}$ TNF- $\alpha$ SNP effect in the overall group patients, in patients with sepsis, and in those with septic shock no significant associations were found (Table 2). Nevertheless, interestingly, the five

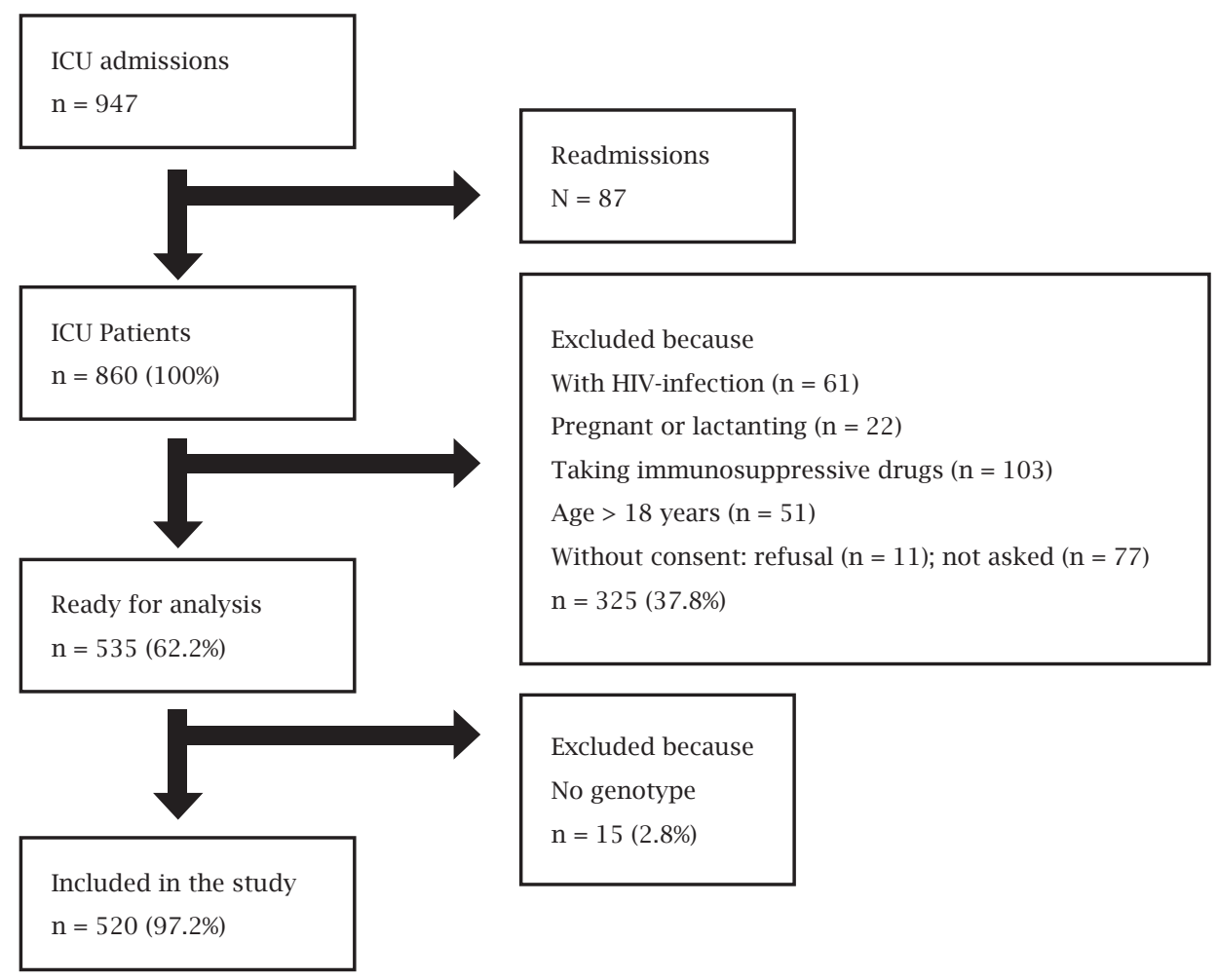

Figure 1: Flow diagram of ICU patients studied between January 2004 and December 2006. 
Table 1. Clinical and demographic data of critically ill patients according to the TNF $\alpha-308 G>A$ SNP genotype groups

\begin{tabular}{|c|c|c|c|c|}
\hline Variables & All patients & With -308A & Without -308A & $\mathbf{p}^{*}$ \\
\hline Frequency ${ }^{\dagger}$ & $520(100)$ & $146(28.1)$ & 374 (71.9) & $0.391^{\mathrm{HW}}$ \\
\hline Male $^{\dagger}$ & $277(54)$ & $74(50.7)$ & $203(54.3)$ & $0.559^{\times 2}$ \\
\hline Medical admission & $433(83.2)$ & $121(27.9)$ & $312(72.1)$ & $0.440^{\mathrm{x} 2}$ \\
\hline Surgical admission & $87(16.8)$ & $28(32.4)$ & $59(67.4)$ & $0.440^{\times 2}$ \\
\hline Sepsis $^{\dagger}$ & $349(67.1)$ & $104(71.2)$ & $245(65.5)$ & $0.272^{\mathrm{x} 2}$ \\
\hline Septic shock ${ }^{\dagger}$ & $248(47.7)$ & 68 (46.6) & $180(48.1)$ & $0.750^{\times 2}$ \\
\hline Age $(\text { years) })^{\ddagger}$ & $57(40-71)$ & $55(39-71)$ & $57.5(40-71)$ & $0.860^{\mathrm{MW}}$ \\
\hline APACH II score $\$$ & $19.5(7.8)$ & $19.6(7.6)$ & $19.4(8.3)$ & $0.833^{\mathrm{ST}}$ \\
\hline SOFA-1 score ${ }^{\ddagger}$ & $6(4-9)$ & $6(4-9)$ & $6(4-9)$ & $0.595^{\mathrm{MW}}$ \\
\hline SOFA-7 score s $^{\ddagger}$ & $5(3-8)$ & $5(3-8)$ & $5(3-8)$ & $0.494^{\mathrm{MW}}$ \\
\hline SOFA-15 score ${ }^{\ddagger}$ & $5(3-8)$ & $5(-8)$ & $5(3-8)$ & $0.850^{\mathrm{MW}}$ \\
\hline SOFA-29 score s $^{\ddagger}$ & $4(3-8)$ & $5(3-9)$ & $3(3-7)$ & $0.054^{\mathrm{MW}}$ \\
\hline ICU mortality ${ }^{\dagger}$ & 171 (32.9) & 49 (33.6) & $122(32.6)$ & $0.837^{\times 2}$ \\
\hline ICU+H mortality ${ }^{\dagger}$ & $239(46)$ & $67(45.9)$ & $172(46.0)$ & $0.984^{\times 2}$ \\
\hline
\end{tabular}

Without -308A: -308GG homozygotes to -308G > A TNF- $\alpha$ SNP; With -308A, -308GA heterozygotes and -308AA homozygotes to -308G > A TNF- $\alpha$ SNP; APACHE-II, acute physiology and chronic health evaluation II; SOFA, sequential organ failure assessment; ICU, intensive care unit; ICU+H, ICU plus hospital; LOS, length of stay; n, number; SD, standard deviation of the mean; IQR, interquartile range; ST, Student's t-test; MW, Mann-Whitney U-test; X2, Pearson Chi-Square test; HW, Pearson Chi-Square test for Hardy-Weinberg equilibrium.

" p-value describes a comparison between with -308A allele and without -308A allele groups

${ }^{\dagger} \mathrm{n}(\%)$

${ }^{\ddagger}$ median $(\mathrm{IQR})$

$\S$ mean $(\mathrm{SD})$

Table 2. Patients' clinical data according -308G > A tumor necrosis factor- $\alpha$ single nucleotide polymorphism genotype groups

\begin{tabular}{|c|c|c|c|c|}
\hline Total & With -308A & Without -308A & $\mathbf{p}^{(\mathrm{X} 2)}$ & \\
\hline Total of ICU patients & $520(100)$ & $146(28.1)$ & 374 (71.9) & 0.391 \\
\hline With sepsis & $349(67.1)$ & $104(71.2)$ & $245(65.5)$ & $0.272^{\mathrm{x} 2}$ \\
\hline With septic shock & $248(47.7)$ & $68(46.6)$ & $180(48.1)$ & 0.750 \\
\hline ICU+H mortality & 171 (32.9) & 49 (33.6) & $122(32.6)$ & 0.837 \\
\hline ICU mortality & $239(46)$ & 67 (45.9) & $172(46.0)$ & 0.984 \\
\hline Septic patients & $349(67.1)$ & $104(71.2)$ & $245(65.5)$ & $0.272^{\mathrm{x} 2}$ \\
\hline With septic shock & 248(71.1) & $68(65.4)$ & $180(73.5)$ & 0.128 \\
\hline ICU+H mortality & 195 (55.9) & $58(55.8)$ & 137 (55.9) & 0.980 \\
\hline ICU mortality & $154(44.1)$ & $45(43.3)$ & $109(44.5)$ & 0.834 \\
\hline Septic shock patients & $248(47.7)$ & $68(46.6)$ & $180(48.1)$ & $0.750^{\times 2}$ \\
\hline ICU+H mortality & $158(63.7)$ & $43(63.2)$ & 115 (63.9) & 0.924 \\
\hline ICU mortality & $132(53.2)$ & $39(57.4)$ & $93(51.7)$ & 0.423 \\
\hline
\end{tabular}

Variables are expressed as number (\%). Without -308A, -308GG homozygotes to -308G > A TNF- $\alpha$ SNP; With -308A, -308GA heterozygotes and -308AA homozygotes to -308G > A TNF- $\alpha$ SNP; ICU, Intensive Care Unit; ICU+H, Intensive Care Unit and Hospital; Mortality, mortality at ICU and ICU plus post-ICU (hospital), measured by number of days; n, number of patients; HW, Pearson Chi-square test for Hardy-Weinberg equilibrium; X2, Pearson Chi-square test. The p-value describes a comparison between patients with and without the data specified at each line and the presence of the -308A allele. 
Table 3. Sequential organ failure assessment scores according to $-308 G>A$ tumor necrosis factor- $\alpha$ single nucleotide polymorphism genotype groups

\begin{tabular}{|c|c|c|c|c|}
\hline Critically ill patients & 520 & 146 & 374 & \\
\hline SOFA 1-7 & $6(3-8)$ & $6(3-8)$ & $6(3-8)$ & 0.988 \\
\hline Septic patients & 349 & 104 & 245 & \\
\hline SOFA 1-7 & $7(4-9)$ & $7(4-9)$ & $7(4-9)$ & 0.839 \\
\hline Septic shock patients & 248 & 68 & 180 & \\
\hline SOFA $1-7,15,29$ & $7(5-10)$ & $8(5-10)$ & $7(5-10)$ & 0.520 \\
\hline SOFA 1-7 & $7(5-10)$ & $8(5-10)$ & $7(5-10)$ & 0.385 \\
\hline
\end{tabular}

Without -308A, -308GG homozygotes to -308G > A TNF- $\alpha$ SNP; With -308A, -308GA heterozygotes and -308AA homozygotes to $-308 \mathrm{G}$ > A TNF- $\alpha$ SNP; n, number of patients; IQR, interquartile range; SOFA, sequential organ failure assessment score obtained daily during the first week from the ICU admission (days 1 to 7), and in the days 15 and 29 described as median (IQR); MW, Mann-Whitney U-test. The p-value describes a comparison between SOFA scores and the presence of the -308A allele.

-308AA patients developed sepsis and septic shock. We also investigated if $-308 \mathrm{G}>\mathrm{A}$ TNF- $\alpha$ genotypes could be affecting organ dysfunction or failure, measured by SOFA scores (days 1 to 7,15 , and 29). Our results show that there were no statistical associations among -308G > A TNF- $\alpha$ genotype groups and SOFA scores in any patient sets (critically ill patients, septic or septic shock patients): SOFA medians obtained during ICU stay (measured in days 1 to 7 , 15 , and 29; with a total of 2889 data) were similar among genotypes (Table 3). Finally, to control for confounding variables, we analyzed the SNP impact with the possible covariates age and SOFA-1 on the outcome of critical illness by binary logistic regression model, but none of genotype were found to be relevant.

\section{DISCUSSION}

In this study patients were recruited from a medical and surgical ICU of the Hospital São Lucas. In agreement with a recent epidemiological study in a Brazilian hospital in the state of Paraná, we found that the main medical cause for ICU admission was sepsis (35\% against $40 \%$ in Kauss et al. ${ }^{29}$ recent study), and the mortality rates at ICU plus follow-up were $46 \%$ in our study compared to $42 \%$ in Kauss et al. ${ }^{29}$

Our study revealed no association between $-308 \mathrm{G}>\mathrm{A}$ TNF- $\alpha$ genotypes and adverse outcomes (sepsis, septic shock, higher organ dysfunction or mortality) from critical illness. Our results demonstrated that the $-308 \mathrm{~A}$ rare allele frequency was $15 \%$, confirming the trend documented in Danish (22\%), ${ }^{24}$ English (20\%), ${ }^{23}$ French $(18 \%),{ }^{17}$ and Spanish subjects (9\%). ${ }^{30}$ The -308 A allele has higher level of inducible and constitutional TNF- $\alpha,{ }^{13,14}$ but its phenotypical effects in sepsis, septic shock, organ dysfunction, and mortality have been contradictory; ${ }^{31}$ while it was perceived in some genetic association studies; ${ }^{16,18}$ in other it was not present. ${ }^{22-24}$

Specifically, in contrast to our study $(n=520$, southern Brazilian population), positive associations between -308A allele and sepsis, septic shock, higher organ dysfunction, and/or mortality were found when Mira et al. ${ }^{17}(\mathrm{n}=89$, France), Tang et al..$^{18}\left(\mathrm{n}=112\right.$, China), O'Keefe et al. ${ }^{21}$ $(\mathrm{n}=152$, USA $)$, and Watanabe et al. ${ }^{48}(\mathrm{n}=113$, Japan $)$ studied the $-308 \mathrm{G}>\mathrm{A}$ SNP in their populations. How can these differences among studies be explained? Some factors may contribute to these findings: first, the TNF- $\alpha$ gene is in the highly polymorphic $6 \mathrm{p} 21$ locus, within the class III region for major histocompatibility complex (MHC), between lymphotxin $a$ (TNF-b) and lymphotxin $b$ genes. ${ }^{49}$ Strong linkage disequilibrium among the alleles creates established haplotypes that affect differently TNF- $\alpha$ expression and activity, and can have diverse effects within each studied population. So, the single -308G > A SNP analysis can cause conflicting results. Second, the immune response involves several molecules (CD14, TLR4, TLR2, MyD88, IRAK, NF-kB, and others) codified by other genes that can interfere in the inflammatory arena causing misleading conclusions. Third, the TNF- $\alpha$ gene product can be changed at different stages (gene transcription, post-transcription, mRNA stability, cleavage to soluble form, and/ or receptor structure or levels), and it can modify circulating TNF- $\alpha$ activity during critical illness affecting patient's outcome. Finally, our larger sample size comparing with previous studies may have produced the contrasting result, although we recognize that Gordon et al. ${ }^{23}$ suggested that 
at least 2,000 patients would be necessary to achieve $90 \%$ power to obtain a p-value of 0.01 in studies involving the -308A allele and septic shock.

For negative results, assessment of power to detect modest effects is crucial, and along with that, careful assessment of the likelihood of a false-positive finding in an apparent significant genetic association should also be made. So when can we state success in a genetic association study? ?2 $^{32}$ A meta-analysis suggested that most reported findings of association are not correct, and that these false-positives studies are probably responsible for the vastness of failures to replication associations between common variants and complex outcomes. ${ }^{33}$ The reasons for this lack of reproducibility have been well discussed, ${ }^{34-36}$ especially between large versus small studies. ${ }^{35}$ Our study was designed to achieve the set of guidelines proposed by Bogardus et al..$^{37}$ recently reviewed by Clark and Baudouin $^{31}$ to examine associations among genetic variants and risk for and outcome from complex diseases. In addition to that, we considered the guidelines stimulate a higher number of genotype studies by the NCI-NHGRI Working Group on Replication in Association Studies. ${ }^{38}$

We did not measure serum TNF levels to correlate with $-308 \mathrm{G}>$ A alleles because other studies have described this relationship clearly. ${ }^{23,39}$ Any meaningful interpretation of serum TNF levels taken at varying time points after the onset of illness and beginning of antibiotics is difficult. ${ }^{20}$ Even in the setting of acute septic shock, an increased serum TNF is not detectable in all patients, ${ }^{40,41}$ because TNF has a short half-life, and is known to be released in pulses, ${ }^{23}$ so genotype associations that correlate with an overall phenotypic response may be more useful than correlation with single point cytokine measurements. Even that $-308 \mathrm{G}>\mathrm{A}$ SNP seems to have a central role in the TNF- $\alpha$ expression, the overall relevance of association studies can be widely questioned. ${ }^{42}$ Considering the main points expressed by critical analysis of association studies, ${ }^{43-45}$ our study has some strengths; I) the SNP has biological reasonability, i.e., there is a plausible effect of the gene product in infection and sepsis; II) we used a quality control system to ensure genotyping accuracy (sequencing verification of the DNA amplified fragment, black controls, and repetitions) in our lab routine; III) the lab technicians were blinded to phenotype and clinical investigators blinded to genotype; IV) genotype distributions were in Hardy-Weinberg equilibrium; ${ }^{45} \mathrm{~V}$ ) the patients were recruited from an unique Caucasian population with similar genetic background, mainly of Portuguese ancestry, but descendants from Italians, Spanish and Germans have also contributed to this gene pool; $; 6,47 \mathrm{VI}$ ) we use precise and universal definitions of sepsis and septic shock, worldwide scores to organ dysfunction, and days instead of categories to mortality determinations.

We recognize that nor haplotyped-based neither cluster-based TNF gene approach can be a limitation and that multiple-marker studies are more precise than the analysis of a single target. Further SNP-array investigations in multi- ple-center should include the TNF SNP alone or in combination with other functionally relevant mutations. Broader advanced studies including additional candidate TNF SNPs and genes such as CD14, TLR4 or TLR2 genes could also help to refine the understanding about sepsis and septic shock predisposition. We are presently investigating some of these possibilities.

There have been several other -308G > A studies published in the critically ill patients with contradictory results. Studies involving genetic polymorphisms and clinical conditions in ICU should be explicitly encouraged, but only well-powered, and large studies will provide definitive answers to this situation. It is important to emphasize that because sepsis is a dynamic and complex process, it is likely that varying and distinct combination of SNPs, as opposed to any SNP alone, interface to impact the outcome of critically ill patients, and we are currently working on that.

\section{CONCLUSION}

In conclusion, our results obtained in 520 critically ill patients from a single ICU center suggest that $-308 \mathrm{G}>\mathrm{A}$ TNF- $\alpha$ SNP alone does not play a major role in the outcome from the critical illness. The presence of the -308A TNF- $\alpha$ allele was not associated to the outcome of sepsis, septic shock, higher organ dysfunction or mortality in critically ill patients in a population from southern Brazil.

\section{ACKNOWLEDGMENTS}

We thank AJG Bos, CAS Ferreira, CL Dornelles, and FB Nunes for their suggestions and P Graebin, LR Fraga, and HS Thurow for technical assistance. This study was financed by Fundação de Amparo à Pesquisa do Rio Grande do Sul and Conselho Nacional de Desenvolvimento Científico e Tecnológico (FAPERGS/MS/CNPq/SESRS; EFP00000829; PPSUS-Edital 002/2009 Process \# 09/0039-3).

\section{REFERENCES}

1. Resche-Rigon M, Azoulay E, Chevret S. Evaluating mortality in intensive care units: contribution of competing risks analyses. Crit Care 2006; 10:103.

2. Poikonen K, Lajunen T, Silvennoinen-Kassinen $\mathrm{S}$ et al. Effects of CD14, TLR2, TLR4, LPB, and IL-6 Gene Polymorphisms on Chlamydia pneumoniae Growth in Human Macrophages In Vitro. Scand J Immunol. 2009; 7:30-9.

3. Medzhitov R, Janeway CA Jr. Innate immunity: the virtues of a nonclonal system of recognition. Cell 1997; 91:295-8.

4. Arancibia SA, Beltran CJ, Aguirre IM Silva P et al. Toll-like receptors are key participants in innate immune responses. Biol Res 2007/ 40:97-112.

5. Dobrovolskaia MA, Vogel SN: Toll receptors, CD14, and macrophage activation and deactivation by LPS. Microbes Infect 2002; 4:903-14.

6. O'Shea JJ, Ma A, Lipsky P. Cytokines and Autoimmunity. Nat Rev Immunol. 2002; 2:37-45. 
7. Locksley RM, Killeen N, Lenardo MJ. The TNF and TNF receptor superfamilies: integrating mammalian biology. Cell 2001; 104:487-501.

8. Schottelius AJ, Moldawer LL, Dinarello CA et al. Biology of tumor necrosis factor-alpha - implications for psoriasis. Exp Dermatol. 2004; 13:193-222.

9. Wood LJ, Nail LM, Gilster A, Winters KA. Cancer chemotherapy-related symptoms: Evidence to suggest a role for proinflammatory cytokines. Oncol Nurs Forum 2006; 33(3):535-42.

10. Wilson AG, di Giovine FS, Blakemore AI, Duff GW. Single base polymorphism in the human tumour necrosis factor alpha (TNF alpha) gene detectable by NcoI restriction of PCR product. Hum Mol Genet. 1992; 1(5):353.

11. Wunderink RG, Waterer GW. Genetics of sepsis and pneumonia. Curr Opin Crit Care 2003; 9(5):384-9.

12. Grohe SS, Stuber F, Book M. TNF-a Promoter Polymorphism in Relation to TNF-a Production and Clinical Status in Cystic Fibrosis. Lung 2006; 184:99-104.

13. Kroeger KM, Carville KS, Abraham LJ. The -308 tumor necrosis factor- $\alpha$ promoter polymorphism effects transcription. Mol Immunol. 1997; 34(5):391-9.

14. Wilson AG, Symons JA, McDowell TL et al. Effects of a polymorphism in the human tumor necrosis factor- $\alpha$ promoter on transcriptional activation. Immunol. 1997; 94:3195-9.

15. Beutler B. Shock and tissue injury induced by recombinant human cachectin. Science 1986; 234(4775):470-4.

16. Stüber F, Petersen M, Bokelmann F, Schade U. A genomic polymorphism within the tumor necrosis factor locus influences plasma tumor necrosis factor-a concentrations and outcome of patients with severe sepsis. Crit Care Med. 1996; 24(3):381-4.

17. Mira JP, Cariou A, Grall F et al. Association of TNF2, a TNFalpha promoter polymorphism, with septic shock susceptibility and mortality: a multicenter study. JAMA 1999; 282(6):561-8.

18. Tang GJ, Huang SL, Yien HW et al. Tumor necrosis factor gene polymorphism and septic shock in surgical infection. Crit Care Med. 2000; 28(8):2733-6.

19. Appoloni O, Dupont E, Vandercruys M et al. Association of Tumor Necrosis Factor-2 Allele with Plasma Tumor Necrosis Factor-alpha Levels and Mortality from Septic Shock. Am J Med. 2001; 110(6):486-8.

20. Waterer GW, Quasney MW, Cantor RM, Wunderink RG. Septic shock and respiratory failure in community-acquired pneumonia have different TNF polymorphism associations. Am J Resp Crit Care Med. 2001; 163(7):1599-604.

21. O'Keefe GE, Hybki DL, Munford RS. The G-A single nucleotide polymorphism at the -308 position in the tumor necrosis factor-alpha promoter increases the risk for severe sepsis after trauma. J Trauma 2002; 52(5):817-25.

22. Reid CL, Perrey C, Pravica V et al. Genetic variation in proinflammatory and anti-inflammatory cytokine production in multiple organ dysfunction syndrome. Crit Care Med. 2002; 30(10):2216-21.

23. Gordon AC, Lagan AL, Aganna E et al. TNF and TNFR polymorphisms in severe sepsis and septic shock: a prospective multicentre study. Genes Immun. 2004; 5(8):631-40.

24. Jessen KM, Lindboe SB, Petersen AL et al. Common TNF- $\alpha$, IL-1 $\beta$, PAI-1, uPA, CD14 and TLR4 polymorphisms are not associated with disease severity or outcome from Gram negative sepsis. BMC Infect Dis. 2007; 18;7:108.

25. American College of Chest Physicians/Society of Critical Care Medicine. Consensus Conference: definitions for sepsis and organ failure and guidelines for the use of innovative therapies in sepsis. Crit Care Med. 1992; 20(6):864-74.

26. Knaus WA, Draper EA, Wagner DP, Zimmerman JE. APACHE II: a severity of disease classification system. Crit Care Med. 1985; 13(10):818-29.

27. Vincent JL, Moreno R, Takala J et al. The SOFA (Sepsis-related Organ Failure Assessment) score to describe organ dysfunction/ failure. On behalf of the Working Group on Sepsis-Related Problems of the European Society of Intensive Care Medicine. Int Care Med. 1996; 22(7):707-10.

28. Lahiri DK, Nurnberger Jr JI. A rapid non-enzymatic method for the preparation of HMW DNA from blood for RFLP studies. Nucl Acids Res. 1991; 19(19):5444.

29. Kauss IA, Grion CM, Cardoso LT et al. The epidemiology of sepsis in a Brazilian teaching hospital. Braz J Infect Dis. 2010; 14(3):264-70

30. Garnacho-Montero J, Aldabo-Pallas T, Garnacho-Montero C et al. Timing of adequate antibiotic therapy is a greater determinant of outcome than are TNF and IL-10 polymorphisms in patients with sepsis. Crit Care 2006; 10(4):R111.

31. Clark MF, Baudouin SV. A systematic review of the quality of genetic association studies in human sepsis. Int Care Med. 2006; 32(11):1706-12.

32. Newton-Cheh C, Hirschhorn JN. Genetic association studies of complex traits design and analysis issues. Mutation Research 2005; 573(1-2):54-69.

33. Lohmueller KE, Pearce CL, Pike M et al. Meta-analysis of genetic association studies supports a contribution of common variants to susceptibility to common disease. Nat Genet. 2003; 33:177-82.

34. Cardon LR, Bell JI. Association study designs for complex diseases. Nat Rev Genet. 2001; 2(2):91-9.

35. Ioannidis JPA, Trikalinos TA, Ntzani EE, Contopoulos-Ioannidis DG. Genetic associations in large versus small studies: an empirical assessment. Lancet 2003; 361(9357):567-71.

36. Todd JA. Statistical false positive or true disease pathway? Nat Genet. 2006; 38(7):731-3.

37. Bogardus ST Jr, Concato J, Feinstein AR. Clinical epidemiological quality in molecular genetic research: The need for methodological standards. JAMA 1999; 281(20):1919-26.

38. NCI-NHGRI Working Group on Replication in Association Studies. Replicating genotype-phenotype associations. Nature 2007; 447(7145):655-60.

39. Louis E, Franchimont D, Piron A et al. Tumour necrosis factor (TNF) gene polymorphism influences TNF-alpha production in lipopolysaccharide (LPS)-stimulated whole blood cell culture in healthy humans. Clin Exp Immunol. 1998; 113(3):401-6.

40. Cohen J, Carlet J. INTERSEPT: An international, multicenter, placebo-controlled trial of monoclonal antibody to human tumor necrosis factor-alpha in patients with sepsis: International Sepsis Trial Study Group. Crit Care Med. 1996; 24:1431-40.

41. Abraham E, Anzueto A, Guttierez G et al. Double-blind randomized controlled trial of monoclonal antibody to human tumour necrosis factor in the treatment of septic shock. The NORASEPT II Study Group. Lancet 1998; 351(9107):929-33.

42. Colhoun HM, McKeigue PM, Davey Smith G. Problems of reporting genetic associations with complex outcomes. Lancet 2003; 2003 8:361(9360): 865-872.

43. Peters DL, Barber RC, Flood EM et al. Methodologic quality and genotyping reproducibility in studies of tumor necrosis factor -308 G-A single nucleotide polymorphism and bacterial sepsis: implications for studies of complex traits. Crit Care Med. 2003; 31(6):1691-6.

44. Vitali SH, Randolph AG. Assessing the quality of case-control association studies on the genetic basis of sepsis. Pediatr Crit Care Med. 2005; 6:S74-7.

45. Trikalinos TA, Salanti G, Khoury MJ, Ioannidis JP. Impact of violations and deviations in Hardy-Weinberg equilibrium on postulated gene-disease associations. Am J Epidemiol. 2006; 15(4):300-9.

46. Salzano FM, Freire-Maia N. Problems in human biology. A study of Brazilian populations. Detroit, Wayne State University Press, 1970.

47. Parra FC, Amado RC, Lambertucci JR et al. Color and genomic ancestry in Brazilians. Proc Natl Acad Sci USA 2003; 100(1):177-82. 
48. Watanabe Y, Muratake T, Kaneko N, Fukui N, Nara Y, Someya T. No ssociation between the tumor necrosis factor-alpha gene promoter polymorphisms and schizophrenia in a Japanese population.Psychiatry Res. 2007 Sep 30;153(1):1-6. Epub 2007 Jun 7.
49. Hajeer AH, Hutchinson IV. Influence of TNFalpha gene polymorphisms on TNFalpha production and disease. Hum Immunol. 2001 Nov;62(11):1191-9. 